\title{
STUDY OF CLINICAL, ELECTROPHYSIOLOGICAL, ULTRASONOGRAPHIC PROFILE IN PATIENTS WITH CARPAL TUNNEL SYNDROME
}

\author{
Revathy $G^{1}$, Velusamy $S^{2}$, Malcolm K. Jeyaraj33, Sakthi Velayutham $S^{4}$, Sowmini P. R5, Arunan $S^{6}$
}

1 Postgraduate Student, Department of Neurology, Government Stanley Medical College, Chennai, Tamilnadu, India.

2 Professor, Department of Paediatric Neurology, Government Stanley Medical College, Chennai, Tamilnadu, India.

${ }^{3}$ Assistant Professor, Department of Neurology, Government Stanley Medical College, Chennai, Tamilnadu, India.

${ }^{4}$ Assistant Professor, Department of Neurology, Government Stanley Medical College, Chennai, Tamilnadu, India.

${ }_{5}^{5}$ Assistant Professor, Department of Neurology, Government Stanley Medical College, Chennai, Tamilnadu, India.

${ }^{6}$ Professor, Department of Neurology, Government Stanley Medical College, Chennai, Tamilnadu, India.

\section{BACKGROUND}

ABSTRACT

Carpal tunnel syndrome is the commonest entrapment neuropathy where median nerve gets entrapped in the tunnel formed by transverse carpal ligament (which is an unyielding fibrous structure) and carpal bones. Carpal tunnel syndrome prevails among individuals whose occupation need repeated wrist movements and also in certain medical conditions like diabetes mellitus, rheumatoid arthritis and hypothyroidism. Electrophysiological study of median nerve at wrist and ultrasonogram of the wrist helps in diagnosing carpal tunnel syndrome and to plan management.

Aim- To evaluate the clinical, electrophysiological and ultrasonographic profile of patients presenting with symptoms of carpal tunnel syndrome (CTS).

\section{MATERIALS AND METHODS}

The study was conducted at Neurology Department, Government Stanley Medical College Hospital between January 2017 and August 2017. All subjects who satisfied the inclusion criteria and given their consent for the study underwent detailed neurological evaluation followed by biochemical investigations, electrophysiological study and ultrasonogram of both wrists. Biochemical investigations done were fasting blood sugar, postprandial blood sugar, thyroid profile, renal function test and rheumatoid arthritis factor. All patients who presented with paraesthesia of hands, mainly tingling or numbness in the median nerve distribution with or without objective signs of Tinel or Phalen were included in the study. Patients who have been previously diagnosed and on treatment for symptoms of carpal tunnel syndrome and other causes of neuropathy were excluded. SPSS software and Chi-square test were used for statistical analysis.

Study Design- A cross-sectional descriptive study.

\section{RESULTS}

Most common age group affected was between 40 and 50 years with Female: Male ratio 3: 1 indicating female predilection. Dominant right hand is commonly involved compared to left hand. Type 2 diabetes was found in $30.6 \%$ and hypothyroidism was found in $11.3 \%$ in the study. In Electrophysiological Study (EPS), moderate grade was found in $50 \%$ of the patients. Ultrasonogram of the wrist had positive correlation irrespective of electrophysiological grading.

\section{CONCLUSION}

Bilateral carpal tunnel syndrome patients had severe electrophysiological grade with positive correlation with ultrasonogram of wrist helping in deciding the mode of treatment- medical versus surgical.

\section{KEY WORDS}

Carpal Tunnel Syndrome, Electrophysiological Study, Median Nerve, Ultrasonogram.

HOW TO CITE THIS ARTICLE: Revathy G, Velusamy S, Jeyaraj MK, et al. Study of clinical, electrophysiological, ultrasonographic profile in patients with carpal tunnel syndrome. J. Evolution Med. Dent. Sci. 2018;7(32):3614-3616, DOI: $10.14260 /$ jemds/2018/811

\section{BACKGROUND}

Carpal tunnel syndrome is the commonest entrapment neuropathy with an incidence of 139 per 100,000 personyears for men and 506 per 100,000 person-years for women.(1)

'Financial or Other Competing Interest': None.

Submission 22-06-2018, Peer Review 23-07-2018,

Acceptance 30-07-2018, Published 06-08-2018.

Corresponding Author:

Velusamy $S$,

Professor, Department of Paediatric Neurology,

Government Stanley Medical College,

Chennai-600001, Tamilnadu, India.

E-mail:drvelsneuro@yahoo.co.in

DOI: $10.14260 /$ jemds $/ 2018 / 811$
The clinical features include pain and paraesthesias in the thumb, radial three and half fingers which exacerbate at night.(1) Sometimes, patient may experience paraesthesia extending to shoulder. The classic test of nerve compression include Tinel's (Light percussion over the volar aspect of wrist elicits tingling sensation) and Phalen manoeuvre (Flexion of the wrist to 90 degrees for 30 to 60 secs aggravate paraesthesia).

The definite diagnostic test for CTS is nerve conduction study with high degree of sensitivity, $56 \%$ to $86 \%$ and specificity $94 \%$ to $99 \%$.(2) It demonstrates a distal compression of the median nerve and excludes other peripheral conditions resulting in similar symptoms.(1,3)

Ultrasonogram of the wrist is also used as a diagnostic tool for CTS as it is readily available, non-invasive and helps 
to assess various parameters of median nerve like size, vascularity, anatomical variations and surrounding structures.(4)

\section{Aim}

To evaluate the clinical, electrophysiological and ultrasonographic profile of patients with carpal tunnel syndrome.

\section{MATERIALS AND METHODS Study Design}

A cross-sectional descriptive study.

\section{Study Population}

Patients above 15 yrs. of age who presented to Neurology Department, Government Stanley Medical College Hospital, Chennai with symptoms and signs of paraesthesia and sensory disturbance of radial three and half fingers with or without objective signs of Tinel's and Phalen. The sample size was 62 .

All patients above 15 yrs. of age with symptoms of paraesthesia and sensory disturbance of radial three and half fingers and also whole hand with extension to shoulder with or without objective signs of Tinel's and Phalen, who had given informed consent were included in the study.

Patients who have been previously diagnosed and on treatment for symptoms of carpal tunnel syndrome and other causes of neuropathy were excluded.

\section{Methodology}

All subjects who satisfied the inclusion criteria and given their consent for the study underwent detailed neurological evaluation followed by biochemical investigations, electrophysiological study and ultrasonogram of both wrists. Biochemical investigations done were fasting blood sugar, postprandial blood sugar, thyroid profile, renal function test and Rheumatoid Arthritis factor. Electrophysiological test.(5)

a. Median motor study recording abductor pollicis brevis. Stimulating wrist and antecubital fossa

b. Ulnar motor study recording abductor digiti minimi. Stimulating at wrist and elbow

c. Median and ulnar $\mathrm{F}$ responses

d. Median sensory response, recording digit 2, stimulating at wrist

e. Ulnar sensory response, recording digit 5 , stimulating at wrist

Table 1. Parameters of Nerve Conduction Study Recorded

\section{Nerve Conduction Studies- Normal Adult Values}

\begin{tabular}{|c|c|}
\hline Median Studies & Comparison Studies \\
\hline $\begin{array}{c}\text { Prolonged distal } \\
\text { motor latency }>4.4 \\
\mathrm{~ms}\end{array}$ & $\begin{array}{c}\text { Difference between distal motor } \\
\text { latency of median and ulnar nerves }> \\
1.1 \mathrm{~ms}\end{array}$ \\
\hline $\begin{array}{c}\text { Prolonged sensory } \\
\text { (digit 2) latency }>3.5 \\
\mathrm{~ms}\end{array}$ & $\begin{array}{c}\text { Difference between sensory latency of } \\
\text { median and ulnar nerves }>0.2 \mathrm{~ms}\end{array}$ \\
\hline \multicolumn{2}{|c|}{$\begin{array}{c}\text { Difference between median and ulnar } \\
\text { digit 4 sensory latencies } \geq 0.5 \mathrm{~ms}\end{array}$} \\
\hline Table 2. Electrophysiological Parameters taken \\
to confirm CTS
\end{tabular}

\begin{tabular}{|c|c|}
\hline Mild CTS & $\begin{array}{c}\text { Prolongation of sensory latency and decrease in } \\
\text { the amplitude of median sensory nerve action } \\
\text { potential }\end{array}$ \\
\hline $\begin{array}{c}\text { Moderate } \\
\text { CTS }\end{array}$ & $\begin{array}{c}\text { Prolongation of distal latency of median motor } \\
\text { nerve in addition to mild CTS criteria }\end{array}$ \\
\hline Severe CTS & $\begin{array}{c}\text { Absence of sensory potential, prolongation of } \\
\text { distal latency and decrease in the amplitude of } \\
\text { median motor nerve }\end{array}$ \\
\hline \multicolumn{2}{|c|}{ Table 3. Electrophysiological Grading of CTS(6) } \\
\hline
\end{tabular}

\section{Ultrasonogram of Wrist}

All the patients underwent ultrasonogram of wrist. Real time high resolution ultrasonogram (Esaote MyLab 6) with 7.5 MHZ linear array transducer were used in the study. Patients were made to sit at a comfortable position facing the radiologist with forearm resting on the table with palm facing up. Median was assessed in transverse and longitudinal planes in the carpal tunnel by references to anatomical landmarks- pisiform bone or the hook of the hamate or the distal wrist crease. The US criteria(7) we use for diagnosing the median nerve compression at the carpal tunnel include increased cross-sectional area proximally to the compression site, usually at the level of the proximal pisiform bone (Normal cross-sectional area of the median nerve is not greater than $9 \mathrm{~mm} 2$ ) nerve flattening (in the transverse section the nerve is at least 3 times wider than it is thickness) and lower echogenicity.

\section{RESULTS}

A total of 62 patients above age 15 yrs. were taken up in the study after applying inclusion and exclusion criteria. Majority of patients were in age group between 41 and 50 yrs. followed by 31 to 40 yrs. and then above 50 yrs. Among 62 patients, $15(24.2 \%)$ were males and 47 (75.8\%) were females which indicate female predilection. Paraesthesia was the commonest symptom and it was present in 57 patients (91.9\%). Tinel's sign was present in 28 (45.2\%) patients and Phalen sign in $26(21.9 \%)$ patients. Among 62 patients, 19 (30.6\%) were diagnosed with type 2 diabetes, 7 (11.3\%) were hypothyroid, 6 (9.7\%) were positive with Rheumatoid arthritis and 3 (4.8\%) were diagnosed with renal failure

Out of 62 patients, $18(29 \%)$ patients had CTS in right hand, 12 (19\%) had left CTS and bilateral CTS in 14 (23\%) and normal electrophysiological study were present in 18 (29\%) out of 62 patients. In bilateral CTS, 12 (85.7\%) were females and $2(14.2 \%)$ were males. In right hand CTS, females were $14(77.8 \%)$ and $4(14.8 \%)$ were males and in left hand CTS females were 9 (75\%) and 3 (25\%) were males.

\begin{tabular}{|c|c|}
\hline Age Group (Years) & Number (n) \\
\hline Above 50 & 11 \\
\hline $41-50$ & 33 \\
\hline $31-40$ & 18 \\
\hline \multicolumn{2}{|c|}{ Table 4. Showing Age distribution of Study Population } \\
\hline
\end{tabular}

All patients who had abnormal electrophysiology of CTS had increase in cross-sectional area with right hand CTS, left hand CTS and bilateral CTS.

\begin{tabular}{|c|c|c|c|}
\hline $\begin{array}{c}\text { Electrophysiological } \\
\text { Grading }\end{array}$ & $\begin{array}{c}\text { Right Hand } \\
(\mathbf{n = 1 8})\end{array}$ & $\begin{array}{c}\text { Left Hand } \\
\mathbf{n = 1 2}\end{array}$ & $\begin{array}{c}\text { Bilateral } \\
\mathbf{n = 1 4}\end{array}$ \\
\hline Mild & $8(44 \%)$ & $4(33 \%)$ & - \\
\hline Moderate & $6(33 \%)$ & $6(50 \%)$ & $6(43 \%)$ \\
\hline Severe & $4(22 \%)$ & $2(17 \%)$ & $8(57 \%)$ \\
\hline \multicolumn{3}{|c|}{ Table 5. Electrophysiology Study of CTS Patients } \\
\hline
\end{tabular}


There was $100 \%$ correlation $(\mathrm{p}<0.05)$ between electrophysiological and ultrasonographic increase in crosssectional area with right hand CTS, left hand CTS and bilateral CTS irrespective of electrophysiological grading of CTS which is statistically significant.

\begin{tabular}{|c|c|}
\hline Ultrasound Parameter & Number (n) \\
\hline Increased cross-section area of median nerve & 44 \\
\hline Nerve flattening & 35 \\
\hline Lower echogenicity & 36 \\
\hline \multicolumn{2}{|c|}{ Table 6. Ultrasonographic Study of CTS Patients } \\
\hline
\end{tabular}

\section{DISCUSSION}

A total of 62 patients (88 hands) were included in the study as having carpal tunnel syndrome clinically. Majority of patients affected were in age group of 40 to 50 years followed by 30 to 40 years with female predominance compared to male and male: female ratio was 1 : 3 . In a study by Vinay et $\mathrm{al},(8)$ the mean age was 44.21 years with female predominance (M: F 3: 11) and also in a study by Kasundra et al,(9) mean age was $43.9 \pm 4$ years and male: female ratio of 13: 79 which was similar in our study.

Commonest symptoms were nocturnal paraesthesia and numbness over radial 3 and half fingers which were present in $91 \%$ of patients with Tinel's sign in $45.2 \%$ and Phalen's in $41.9 \%$. In a study by Kasundra GM et al,(9) Tinel's test was present in $78.5 \%$ and Phalen's test was positive in $84.9 \%$. In a study by Tay LB et al,(10) $70 \%$ of patients showed nocturnal paraesthesias.

Majority of patients (43.5\%) had no specific cause. Type 2 Diabetes Mellitus (DM) was present in $30.6 \%, 11.3 \%$ were hypothyroid, 9.7\% were positive with Rheumatoid arthritis and $4.8 \%$ were diagnosed with renal failure which was similar to study done by Hussein Mohammed Malibary et al.(11) DM was the most common associated disease to CTS $35.9 \%$ followed by hypothyroidism $14.1 \%$.

Commonest electrophysiological grading in the study was moderate grade, while severe grading of CTS is noted in patients with bilateral CTS.

In our study, ultrasonogram showed increase in crosssectional area of median nerve at wrist in all 44 (100\%) patients, which had abnormal electrophysiological study suggestive of CTS. Sharma M et al from Chandigarh(12) and Min-Kyu Kim et al(13) have studied the role of ultrasonography in diagnosis of carpal tunnel syndrome and found that there was high degree of correlation between ultrasonography and electrophysiological parameters in patients with CTS. Kapuścińska et al also reported that all patients in their study $(n=62)$ had median nerve compression in ultrasonographic study.(14) Limitations in the study were small sample size and early CTS could have been diagnosed using combined sensory index, which was not measured in the present study.

\section{CONCLUSION}

Electrophysiological study is the gold standard in diagnosing and grading the severity of CTS. Most common electrophysiological abnormality with bilateral CTS is absent median sensory nerve action potential. Ultrasonogram of the wrist showing increase in cross-sectional area of median nerve irrespective of severity of electrophysiological grading of CTS. Ultrasonogram also helps to rule out structural lesions like ganglion or neuroma and to decide on medical versus surgical treatment.

\section{REFERENCES}

[1] Bland JD. Do nerve conduction studies predict the outcome of carpal tunnel decompression? Muscle Nerve 2001;24(7):935-40.

[2] Jablecki CK, Andary MT, Floeter MK, et al. Practice parameter: electrodiagnostic studies in carpal tunnel syndrome. Report of the American Association of Electrodiagnostic Medicine, American Academy of Neurology and the American Academy of Physical Medicine and Rehabilitation. Neurology 2002;58(11):1589-92.

[3] Mondelli M, Giannini F, Vecchierelli B, et al. Diagnostic pathway in carpal tunnel syndrome. Riv Neurobiol 2000;46:301-5.

[4] Beekman R, Visser LH. Sonography in the diagnosis of carpal tunnel syndrome: a critical review of the literature. Muscle Nerve 2003;27(1):26-33.

[5] Preston DC, Shapiro BE. Electromyography and neuromuscular disorders: clinical electrophysiologic correlations. 2nd edn. Elsevier Health Sciences 2005.

[6] Padua L, LoMonaco M, Gregori B, et al. Neurophysiological classification and sensitivity in 500 carpal tunnel syndrome hands. Acta Neurol Scand 1997;96(4):211-7.

[7] Klauser AS, Faschingbauer R, Bauer T, et al. Entrapment neuropathies II: carpal tunnel syndrome. Semin Musculoskeletal Radiol 2010;14(5):487-500.

[8] Goyal V, Bhatia M, Padma MV, et al. Electrophysiological evaluation of 140 hands with carpal tunnel syndrome. J Assoc Physicians India 2001;49:1070-3.

[9] Kasundra GM, Sood I, Bhargava AN, et al. Carpal tunnel syndrome: analyzing efficacy and utility of clinical tests and various diagnostic modalities. J Neurosci Rural Pract 2015;6(4):504-10.

[10] Tay LB, Urkude R, Verma KK. Clinical profile, electrodiagnosis and outcome in patients with carpal tunnel syndrome: a Singapore perspective. Singapore Med J 2006;47(12):1049-52.

[11] Malibary HM, Al-Najjar AT, Yassen DM, et al. Clinical profile of carpal tunnel syndrome in a teaching hospital. Pak J Med Sci 2013;29(1):119-21.

[12] Sharma M, Prabhakar S. Role of ultrasonography in the diagnosis of carpal tunnel syndrome. Annals of Indian Academy of Neurology 2007;(10 Suppl 2):124.

[13] Kim MK, Jeon HJ, Park SE, et al. Value of ultrasonography in the diagnosis of carpal tunnel syndrome: correlation with electrophysiological abnormalities and clinical severity. J Korean Neurosurg Soc 2014;55(2):78-82.

[14] Kapuścińska K, Urbanik A. High-frequency ultrasound in carpal tunnel syndrome: assessment of patient eligibility for surgical treatment. Journal of Ultrasonography 2015;15(62):283-91. 